\title{
The Policy Relevance of Personality Traits
}

\section{Bleidorn, Wiebke}

2019-12

Bleidorn, W , Hill , P L , Back , M D , Denissen , J J A , Hennecke , M , Hopwood , C J , Jokela , M , Kandler , C , Lucas , R E , Luhmann , M , Orth , U , Wagner , J, Wrzus , C , Zimmermann , J \& Roberts , B 2019 , ' The Policy Relevance of Personality Traits ' , American Psychologist, vol. 74 , no. 9 , pp. 1056-1067 . https://doi.org/10.1037/amp0000503

http://hdl.handle.net/10138/324764

https://doi.org/10.1037/amp0000503

acceptedVersion

Downloaded from Helda, University of Helsinki institutional repository.

This is an electronic reprint of the original article.

This reprint may differ from the original in pagination and typographic detail.

Please cite the original version. 
The Policy Relevance of Personality Traits

Wiebke Bleidorn, University of California, Davis, United States

Patrick L. Hill, Washington University in St. Louis, United States

Mitja D. Back, Westfälische Wilhems-Universität Münster, Germany

Jaap J. A. Denissen, Tilburg University, The Netherlands

Marie Hennecke, Universität Siegen, Germany

Christopher J. Hopwood, University of California, Davis, United States

Markus Jokela, University of Helsinki, Finland

Christian Kandler, Universität Bremen, Germany

Richard E. Lucas, Michigan State University, United States

Maike Luhmann, Ruhr-Universität Bochum, Germany

Ulrich Orth, Universität Bern, Switzerland

Jenny Wagner, Universität Hamburg, Germany

Cornelia Wrzus, Universität Heidelberg, Germany

Johannes Zimmermann, Universität Kassel, Germany

Brent Roberts, University of Illinois at Urbana-Champaign, United States

Correspondence concerning this article should be addressed to Wiebke Bleidorn, Department of Psychology, University of California Davis, One Shields Avenue, Davis, CA 95616, United

States. E-mail: wiebkebleidorn@gmail.com. The authors are members of the Personality Change Consortium (PCC).

Running head: POLICY RELEVANCE OF PERSONALITY

In press: American Psychologist 


\begin{abstract}
Personality traits are powerful predictors of outcomes in the domains of education, work, relationships, health, and well-being. The recognized importance of personality traits has raised questions about their policy relevance - that is, their potential to inform policy actions designed to improve human welfare. Traditionally, the use of personality traits in applied settings has been predicated on their ability to predict valued outcomes, typically under the assumption that traits are functionally unchanging. This assumption, however, is both untrue and a limiting factor on using personality traits more widely in applied settings. In this paper, we present the case that traits can serve both as relatively stable predictors of success and actionable targets for policy changes and interventions. Though trait change will likely prove a more difficult target than typical targets in applied interventions, it also may be a more fruitful one given the variety of life domains affected by personality traits.
\end{abstract}

Public significance statement: This paper presents the case that personality traits can serve both as predictors of success and actionable targets for policy changes and interventions. The field of personality psychology has now amassed evidence necessary to address the policy relevance of personality traits. To that end, we pose and answer critical questions regarding personality traits and their applicability for policy initiatives in applied settings.

Keywords: Personality; Traits; Big Five; Policy; Interventions 
Personality traits predict outcomes in virtually all major life domains (Heckman \& Kautz, 2012; Ozer \& Benet-Martinez, 2006; Roberts, Kuncel, Shiner, Caspi, \& Goldberg, 2007; Soto, in press), including educational attainment (Noftle \& Robins, 2007), occupational status (Damian, Spengler, \& Roberts., 2017), income (Denissen et al., 2018), job satisfaction (Schwaba, Robins, Grijalva, \& Bleidorn, in press), relationship success (Wagner, Becker, Lüdtke, \& Trautwein, 2015), childbirth (Jokela, Kivimäki, Elovainio, \& Keltikangas-Järvinen, 2009), divorce (Roberts \& Bogg, 2004), and physical health (Kern \& Friedman, 2008); all at a magnitude similar to or higher than widely accepted determinants of life success, such as socioeconomic status or education (Roberts et al., 2007). Moreover, phenotypic (Kotov, Gamez, Schmidt, Watson, 2010; Leising \& Zimmermann, 2011), genetic (Rosenström et al., in press), and structural (Wright \& Simms, 2015) links between personality and psychopathology are so strong that the most promising evidence-based alternative to the categorical model of psychiatric diagnosis is a system organized around personality traits (Krueger et al., 2018).

Given the importance of personality traits for individual and societal success, why aren't they considered more often as actionable targets for policy changes and interventions? At least part of this question has to do with common assumptions about the nature of personality. Most importantly, there has been a tendency to conceptualize personality traits as a stable cause of life outcomes (McCrae \& Costa, 2008). From this perspective, traits are useful as static predictors and selection factors, but of little consideration for policy changes and interventions that could promote growth and well-being. However, the field of personality psychology has now amassed a large body of evidence showing that personality traits continue to change throughout the lifespan (Roberts, Walton, \& Viechtbauer, 2006), sometimes in response to environmental influences (Bleidorn, Hopwood, \& Lucas, 2018), including purposeful interventions (Roberts, 
Luo, Chow, Su, \& Hill, 2017). Critically, these changes can shape peoples' successes and failures in life. Personality traits may thus occupy a particularly sweet spot at the interface of social science and public policy - broad and enduring enough that they impact a host of important life outcomes, yet malleable enough to serve as potentially powerful targets for interventions designed to improve public welfare.

A fair evaluation of the policy relevance of personality requires an understanding of the nature of traits as both stable and changeable constructs. In this paper, we review the current state of evidence regarding stability and change in personality traits and address critical questions (Table 1) concerning their applicability for policy initiatives in applied settings.

\section{What are personality traits?}

Personality traits can be defined as the relatively enduring patterns of thoughts, feelings, and behaviors that distinguish individuals from each other (Allport, 1961). Although it is sometimes assumed that traits are purely descriptive summaries of behavior, we conceptualize traits as factors that can impact life outcomes by generating thoughts, feelings, and behaviors, especially in ambiguous or novel situations (Caspi \& Moffitt, 1993; Funder, 1991; Roberts \& Jackson, 2008).

The most important reason that traits are relevant to public policy is that their impacts are enduring. A large body of longitudinal research has shown that trait levels assessed in early life stages predict important outcomes later in life (Roberts, et al., 2007). For example, Moffitt et al. (2011) found that low levels of childhood self-control predict a range of maladaptive outcomes in adulthood including poor physical health, substance dependence, and financial problems. The childhood effects of self-control held even when controlling for children's intelligence, family 
background, and social class as well as for the mistakes (e.g., school problems) they made as adolescents.

A persistent preoccupation in personality psychology has involved questions about the structure and content of traits, such as "How many traits are there?" and "How are they related to each other?". In this paper, we focus primarily on the Big Five taxonomy of personality traits: openness to experience, conscientiousness, extraversion, agreeableness, and neuroticism/emotional stability (John \& Srivastava, 1999). Although there are many potential broader and narrower traits to consider (Ashton \& Lee, 2007; Mõttus et al., 2017; Markon, Krueger, \& Watson, 2006), the Big Five represent a viable balance between conceptual breadth, descriptive fidelity, and generalizability across samples and measures, and to a certain degree also across cultures (Costa, McCrae, \& Löckenhoff, 2019; McCrae et al., 2000). Most other traits can be understood as embedded within a hierarchical Big Five framework. So, while the Big Five offer a highly useful level to enter the personality hierarchy, they do not reflect the final word on the structure or content of personality which can be much more inclusive.

\section{What do we mean by personality trait change?}

There is not one single answer to the question "how stable or changeable is personality?" because of the different ways in which stability and change can be quantified (Morey \& Hopwood, 2013), and because some people's life trajectories might be better captured by the concept of trait change than others (Baumeister \& Tice, 1988; Reise \& Waller, 1993). Three indices are particularly relevant for drawing policy-relevant inferences about the stability and 
changeability of personality traits $^{1}$ : rank-order consistency, mean-level change, and individual differences in change (Specht et al., 2014).

Rank-order consistency reflects the degree to which the relative ordering of individuals on a trait is maintained over time. It is the type of stability to in questions like, "If you are more agreeable than your friend today, will you be more agreeable than your friend a year from now?", "will relatively shy adolescents develop into relatively shy adults?" or "what is the reteststability of a particular personality trait measure?".

Whereas rank-order stability indicates the degree to which different people experience more or less change relative to one another, mean-level change reflects the degree to which a trait decreases or increases among all people in a population or group, on average (Mroczek \& Spiro, 2003; Small, Hertzog, Hutsch, \& Dixon, 2003). This type of change refers to absolute increases or decreases (gains or losses) in specific personality traits over a pre-specified period of time and age for a population of individuals. It can be used to examine whether people's personality traits change during major life transitions (van Scheppingen et al., 2016; van Scheppingen, Denissen, \& Bleidorn, in press), whether people tend to increase or decrease in certain traits as they age (Roberts et al., 2006), and which stage of the lifespan is associated with the most pronounced gains or losses (Wortman, Lucas, \& Donnellan, 2012).

In contrast to a focus on stability and change at the aggregate level, investigations into individual differences in personality change focus on patterns of personality development at the level of the person (Schwaba \& Bleidorn, 2018). Questions about individual differences in change ask how closely individuals conform to vs. deviate from the overall population trends of mean-level change. Some people show more or less pronounced changes in their personality

\footnotetext{
${ }^{1}$ This is assuming that the measures show measurement invariance over time.
} 
traits than the average trends. For instance, although most people become more conscientious during the transition from adolescence to early adulthood, some individuals remain stable in this trait or even show significant declines (Bleidorn, 2012; Borghuis et al., 2017). Individual deviations from normative patterns of change imply that interventions could be used to shift trajectories in a more adaptive direction.

Figure 1 illustrates the differences between the three types of change. Each panel shows the hypothetical trajectories of four individuals who were assessed on some trait (e.g., conscientiousness) at baseline and follow-up. In panel A, the mean-level across these participants does not change; however, the rank ordering is different across assessments and there is significant individual-level change. In panel B, all participants decrease in trait-levels indicating significant mean-level change. However, the rank ordering stays the same, and there is no variance in individual trajectories. In panel C, all individuals start with similar trait levels at baseline but fan out at the follow-up assessment. As such, there is no mean-level or rank-order change, but each individual has a different trajectory, indicating individual differences in change.

We next provide a brief overview of the current state of evidence for change in Big Five personality traits across the lifespan by integrating the results of studies that focused on these different indices of change. In doing so, we aim to provide a more complete picture of the stability and changeability of personality traits across different life stages.

\section{How stable and changeable are personality traits?}

Once a niche topic, personality change has become one of the most widely studied phenomena in personality science and beyond. A general conclusion of this research is that personality traits are quite - but not completely - stable over time. Several meta-analyses (e.g., Roberts \& DelVecchio, 2000) found estimates of personality rank-order correlations in the range 
of .4 to .6 over 10-year time lags. More recently, research indicated that the long-term rank-order personality stability over many decades averaged about 2 across 30 or more years (Damian et al., in press). Historically, many researchers have mistaken the phrase relatively stable to mean that personality traits do not change. However, the rank-order consistencies of personality traits are - at least over the long-term—actually quite similar to other constructs that are often considered malleable in policy discussions, such as income, life satisfaction, or self-esteem (Fujita \& Diener, 2005; Orth \& Robins, 2014).

Another important finding to emerge from this literature is that personality traits increase in rank-order stability, peaking between the ages of 50 and 60 , with a plateau or decrease after that decade. This curvilinear relationship between age and rank-order stability appears to generalize across trait domains, assessment methods, and cultures (Costa et al., 2019; Kandler et al., 2010). The finding that personality traits are most prone to change at the beginning (before age 30) and the end of life (after age 70) provides important information about the most effective times for personality interventions suggesting that young adulthood and old age may be especially sensitive periods for personality change.

As noted above, research on rank-order consistency provides an important but incomplete picture of the stability and changeability of personality traits. In fact, when considering meanlevel change in personality traits, a dramatically different story arises. Decades of research has amassed evidence to show that personality traits continue to change throughout the life span and that these changes may be quite substantial, particularly during adolescence and early adulthood (for reviews, see Bleidorn \& Hopwood, 2018; Roberts et al., 2006; Specht et al., 2014). Specifically, most young adults tend to increase in traits that are considered socially desirable such as emotional stability, conscientiousness, and agreeableness (Bleidorn, 2015). These mean- 
level trends generalize across cohorts, genders, and samples from different cultures (Bleidorn et al., 2013; Wortman et al., 2012). Alluding to young adults' seemingly increasing capacity to become productive contributors to society, this pattern has been often referred to as the maturity principle of personality development (Roberts \& Mroczek, 2008).

However, not everyone follows these normative trends. There is robust evidence for substantial individual differences in personality trait change throughout the lifespan. Again, individual differences in personality change appear to be most pronounced during young adulthood (Schwaba \& Bleidorn, 2018) providing further support for theories that consider this life stage as a critical period for personality development (Roberts \& Mroczek, 2008).

The aforementioned findings have led to several conclusions regarding the nature of traits as changeable constructs. First, their relatively stable nature notwithstanding, personality traits can and do change throughout the life span. This finding of continuity and change is not a contradiction in terms, as most, if not all human attributes from the simple (e.g., height) to the complex (e.g., cognitive ability) show a combination of stability and change. Second, personality traits show robust mean-level changes across the lifespan, especially in young adulthood. Third, most of the trait changes in young and middle adulthood are positive (i.e., in socially desirable ways). Fourth, there are substantial individual differences in personality change indicating that subsets of people change differently than the norm.

\section{What drives personality change?}

It has been common to associate personality traits with the idea that they are genetic, heritable, and therefore unchangeable through environmental influences or interventions (Roberts \& Jackson, 2008). In fact, this idea has been fostered by personality scientists themselves. Proponents of this ontogenetic perspective consider traits as "endogenous 
dispositions that follow intrinsic paths of development essentially independent of environmental influences" (McCrae et al., 2000, p. 173). According to this perspective, the high stability and heritability are key features of personality traits that make them such viable predictors of life outcomes. However, this perspective has also led to one of the primary objections raised against using personality traits in applied settings where human capital, and therefore change, is a priority. Why employ concepts that are out of the reach of intervention because they are so strongly tied to biology?

A radically different perspective has been offered by sociogenic approaches that emphasize the role of environmental influences for personality trait change (e.g., Roberts \& Wood, 2006). From this perspective, external influences including life events and purposeful interventions can lead to changes in personality traits to the degree that they modify, interrupt, or redirect people's life trajectories by altering their relatively stable patterns of thoughts, feelings, and behavior.

In recent years, several longitudinal behavioral genetic studies have put these two contrasting perspectives to a test (Bleidorn, Kandler, \& Caspi, 2014; Briley \& Tucker-Drob, 2014). This literature converges on at least three critical findings. First, the relative influence of heritable factors on personality differences is not constant: Although substantial throughout lifespan, it peaks during adolescence and early adulthood. Second, environmental influences on personality differences become more important during early adulthood. Third, both genetic and environmental influences contribute to both stability and change in personality traits. These findings refute the idea that traits are purely biological, genetic, and therefore unchanging dispositions that are immune to the influence of environmental input. Yes, personality traits are "biological" in the sense that they, like virtually all individual differences, are both biological by 
necessity and have some genetic basis (Turkheimer, 2000). But being based on some biological mechanisms does not mean that traits are unchanging.

Which of the specific environmental factors do matter for personality change, however, is a different question. To address this question, a growing number of studies have examined whether changes in personality traits can be linked with certain life experiences (Bleidorn et al., 2018; Denissen, Luhmann, Chung, \& Bleidorn, 2018; Jokela et al., 2009; Lüdtke, Roberts, Trautwein, \& Nagy, 2011; Schwaba, Luhmann, Chung, Denissen, \& Bleidorn, 2018). This literature has produced robust evidence that life experiences are related to personality change and that different experiences may be differentially related to specific trait domains. For example, romantic relationship experiences - and the first romance in particular - appear to be related to trait changes (e.g., Wagner et al., 2015). Similarly, certain work experiences seem to foster personality maturation as indicated by increases in emotional stability, agreeableness, and conscientiousness (e.g., Hudson et al., 2012). Notably, such effects are not limited to the sensitive period of young adulthood. There is growing evidence for associations between life experiences and personality change throughout the lifespan (e.g., Kandler, Kornadt, Hagemeyer, \& Neyer, 2015; Wagner, Ram, Smith, \& Gerstorf, 2016). For instance, major late-life transitions such as retirement are associated with personality change in older adulthood (Bleidorn \& Schwaba, 2018; Schwaba \& Bleidorn, in press).

In summary, there is robust evidence for the importance of both genetic and environmental influences on personality stability and change. Whereas genetic influences appear to be more important in adolescence and early adulthood, environmental influences become increasingly important over the life course. A natural question to arise from this research is which environmental factors matter and how they influence traits. Perhaps even more important 
to discussions of the policy relevance of personality traits is the question whether we can purposefully change someone's personality. In the next section, we review the literature on personality interventions.

\section{Can personality traits be changed through intervention?}

Although the idea of changing personality may appear novel, it is implicitly interwoven into educational curricula, as teachers frequently focus on promoting self-control, curiosity, or integrity in their students. The desire for personality change is also reflected in the everexpanding literature on self-improvement - a random walk through the self-help section in any given book store makes it clear that there is a market for personality interventions. Many people want to improve their personality - to be more organized, less stressed, more outgoing, or more self-controlled (Hudson \& Fraley, 2015) - and are willing to invest time and money to accomplish these goals. Despite widespread public interest in this topic, the literature on personality change through direct intervention has only recently taken root in personality psychology (Mroczek, 2014; Shanahan, Hill, Roberts, Eccles, \& Friedman, 2014).

Indeed, non-clinical interventions in personality psychology are rare. In one example of such research, a mindfulness intervention for medical students resulted in changes in the traits of conscientiousness, agreeableness, empathy, and emotional stability (Krasner et al., 2009). Similarly, a social skill training program for recovering substance abusers led to increases in agreeableness, conscientiousness and emotional stability (Piedmont, 2001; see also Oei \& Jackson, 1980); and a cognitive training intervention for older adults was associated with changes in openness to experience (Jackson, Hill, Payne, Roberts, \& Stine-Morrow, 2012). These studies provide initial evidence that traits can be changed through active intervention. 
To date, the best evidence that personality traits can be changed has come from intervention studies of psychotherapy effectiveness. It has been uncommon for therapists to focus on changing personality traits per se. However, it is very common for clinicians to include personality trait measures in their exhaustive batteries of outcomes used to validate their intervention techniques. In fact, work dating back to the 1950s suggested that psychotherapy led to personality trait change (Shapiro \& Shapiro, 1982; Smith, Glass, \& Miller, 1980), and more recent studies support this conclusion. For example, after a 20 -week cognitive behavior therapy intervention aimed to treat depression, patients had also changed on a number of personality traits, most notably in extraversion and neuroticism (Vittengl, Clark, \& Jarrett, 2003).

A recent meta-analysis of over 200 intervention studies (Roberts et al., 2017) found that clinical interventions lead to marked changes in personality traits, especially neuroticism. The magnitude of decreases in neuroticism following psychotherapy was quite large by developmental standards (half of a standard deviation). In fact, the magnitude of changes experienced in a few months of psychotherapy was around half of that found across the adult lifespan for neuroticism. Importantly, the change experienced as a result of therapy did not fade with time. Studies that tracked patients during the years after the termination of therapy found little or no return to baseline indicating that the changes experienced in therapy could be long lasting.

In summary, research in personality and clinical science provides evidence that personality traits can be changed through intervention. Independent of the particular trait or target population of interest, critical to all personality interventions is a thorough understanding of the underlying process of change. This invites the question "how can interventions get under the skin and lead to enduring changes in personality traits?". 


\section{How can personality traits be changed?}

The increased recognition of personality traits as changeable constructs has led to a recent flurry of theoretical papers and empirical studies dedicated to identifying the ingredients for effective personality interventions (Allemand \& Flückiger, 2017; Geukes, van Zalk, Back, 2018; Hennecke, Bleidorn, Denissen, \& Wood, 2014; Hopwood, 2018; Roberts, Hill, \& Davis, 2017; Wrzus \& Roberts, 2017). Virtually all of these accounts - while emphasizing different details - view personality change as a bottom-up process. A key ingredient of this process are personality states - the material manifestation of traits that are similarly made up of the thoughts, feelings, and behaviors exhibited in any given moment. People frequently act in ways that are inconsistent with their dispositional tendencies as evidenced in a less than perfect relation between states and traits (correlations are commonly $r=.5$ and below; Fleeson, 2001). Withinperson state deviations from trait averages are intuitive: It would be unusual for even the most extraverted person to be talkative and gregarious at a monastery, and most people can get themselves somewhat organized for a job interview even if they are generally low in conscientiousness.

Distinguishing between states and traits while also acknowledging their intimate linkage is critical to understanding how traits might change. Indeed, theory and research suggest that recurrent and enduring changes in personality states drive changes in personality traits. For example, Hennecke and colleagues (2014) proposed that purposeful - or self-regulated personality trait change can occur under three conditions: First, people must consider trait changes as desirable or instrumental means to advancing superordinate goals. Second, people must consider personality state changes feasible and be capable of implementing them. Third, people must frequently engage in new personality states, so that these states turn into habits and 
eventually in enduring trait changes, should they be related to changes in people's self-concept (Roberts \& Wood, 2006).

For example, many people desire to be more conscientious, especially when they are dissatisfied with certain aspects of their lives such as their academic or occupational success (Hudson \& Fraley, 2015). To the degree that they think changes in their conscientiousness are feasible, they may modify their momentary states to be more conscientious by regularly checking to-do lists and monitoring progress on medium-term goals. Over time, changed habits may modify their generalized self-concept - and they may begin to see and describe themselves as more conscientious. Changes in personality states and self-concept might also be parallel processes that reinforce each other in a corresponsive fashion. That is, changes in states may lead to changes in people's self-concept which can, in turn, promote identity-confirming changes in personality states (Borghuis et al., in press; Roberts \& Wood, 2006).

This framework may also help explain why people don't change their personality traits more often. Only to the degree that all of the aforementioned conditions are fulfilled, successful personality trait change can be expected. Having a desire to change is not sufficient if a person lacks the capacity to implement changes; and having both the desire and the ability to change may still not result in enduring personality trait change if not shown habitually. To be clear, such habit changes can be of emotional, behavioral, or cognitive nature. For instance, cognitive approaches to psychotherapy focus on changing thoughts, exposure-based approaches focus on changing feelings, and skills-training approaches focus on changing behavior. In all three cases, the idea is that habit change in one domain spreads to broader changes in the other two. To the degree that such changes are recognized across domains, they may ultimately lead to changes in individual's self-concepts, at which point we would say that personality change has occurred. 
Indeed, such changes will be picked up by standard (self-report) personality measures only to the extent that people also change their self-concept.

In summary, there is evidence that personality traits can be changed through interventions and that such interventions will involve relatively enduring changes of people's personality states and self-concepts. Before designing policy around personality changing interventions, however, one must consider the potential benefits and drawbacks of such an approach.

\section{Why not focus on something that is easier to change?}

Many scientists, practitioners, and lay people hesitate at the idea of intervening to change personality traits. Indeed, the most prevalent world view in clinical psychology derives from a cognitive-behavioral framework where clinicians are taught to focus on changing symptoms or proximal thoughts and behaviors, such as rumination. One of the key features of this framework was a principled withdrawal from more ambitious, longer-term, approaches targeting personality change (Kazdin, 1980). This leads to some challenging questions, such as "why focus on personality when focusing on behavior already works?"

There are several reasons why one might want to consider changing personality traits in educational, clinical, and occupational settings. First, a focus on more proximal behaviors and thoughts, or what we would consider personality states, may lead to short-term adaptations but not to long-term change. For example, it is common to assume that a state change produced by a short-term intervention is sufficient evidence for a potential long-term trait change. This inference is typically made in the absence of data showing that either the short-term change in a state persists or translates into long term shifts in related constructs, such as traits. In contrast, 
adopting the goal of actually changing traits engages the interventionist with the idea that the change should be something that remains long after the intervention.

A second reason to pursue personality change is that it is already the implicit goal in many societal interventions, as well as most therapeutic approaches. For example, the goal of education is often described as imparting knowledge onto the individual and ideally arming that individual with the love of learning. The hope is that in the future, the successful student will be a productive citizen who can learn new things and bring to bear their knowledge on important life decisions; the goal of this education is not a temporary bump in knowledge that disappears with time. Moreover, educators do not expect students to suddenly abandon their love of learning, if they are so fortunate as to acquire it. Similarly, the goal of therapy is to arm a patient with the skills to manage their lives without the constant intervention of a therapist. Indeed, therapists would like their patients to emerge from therapy with the ability to handle not only similar situations to those that have caused them problems in the past, but also new situations that may pose similar risks. Though not identical to the processes we described above, this type of change — the relatively permanent acquisition of knowledge, motivations, and skills that will serve a person in future unknown and unpredictable circumstances - is strikingly similar to personality trait change. This is where the fact that personality traits are both consistent and changeable becomes critical. In contrast to short-term and single-shot approaches to changing individual behaviors or symptoms that may provide immediate benefits but have relatively limited long-term implications, targeting personality traits through sustained changes in states promises to provide individuals with "skills" for success across future contexts and settings.

A third reason is implicit in the evidence that personality traits appear to predict outcomes across life domains. As such, interventions that target personality trait change should 
benefit the individual in ways that extend outside of the initial target domain (Hill \& Jackson, 2016). Educational interventions, for instance, should be encouraged by the possibility that efforts to increase students' conscientiousness may hold benefits for that student across academic, work, relationship, and community contexts (Roberts et al., 2007). The narrow behaviors that have been the preferred targets of intervention in applied fields may not lead to broad improvements that generalize across contexts. Consequently, in order to enact broader benefits for the participants, interventionists may wish to target personality traits instead of more contextualized constructs.

\section{Policy implications}

The purpose of this paper was to review the current state of knowledge about personality trait change in terms of its implications for public policy. Our premise is that closing gaps between common misconceptions of the nature of traits and the empirical literature is critical for leveraging personality change to advance public welfare. Our most general assertion is that personality traits are both stable and changeable, which makes personality trait change a powerful and hitherto relatively underused resource for policy makers. The success of specific practices, interventions, and laws designed to improve the human condition depends at least in part on an informed understanding of when, what, who, and how to intervene. In this section, we discuss the implications of the evidence on personality trait change for public policy.

When? The current body of evidence offers some guidance about the when to intervene. For instance, the transition from adolescence to adulthood has been identified as a particularly critical period. During this life stage, traits tend to change the most, typically in the direction of greater social and psychological maturity (Bleidorn, 2015). Moreover, there may be generally 
more payoff for changing a person early in their life relative to late in their life because changes will have more time to impact life outcomes. Indeed, if someone could, for instance, increase their conscientiousness in adolescence and young adulthood, this could elicit a cascade of positive outcomes, such as better educational success, relationship stability, and health outcomes (Takahashi, Edmonds, Jackson, \& Roberts, 2014). Similarly, decreasing levels of neuroticism could significantly reduce one's likelihood of experiencing negative life events and developing mental or physical health problems (Ormel et al., 2013).

As such, interventions designed to enhance maturation might be particularly powerful if implemented in adolescence and young adulthood. At the same time, it is worth noting that, based on normative trends in personality development (Roberts et al., 2006), young adults are likely to mature even without intervention. Indeed, this period presents an interesting developmental period wherein rank-order stability is low relative to later points in the lifespan, suggesting a greater potential for change, and yet the general mean-level trends evidenced would suggest this period is one of general personality maturation in the absence of intervention. As such, in some cases it may be more cost effective to let normative change take its course rather than to intervene, or to target interventions to young adults who deviate from the normative, maturing trajectory in a negative direction. To be clear, we are not suggesting that policy should exclusively target young adults given that personality traits are open to change throughout the lifespan (e.g., Specht et al., 2014). The more general point is that is decisions about when to implement policy should explicitly consider established evidence about personality stability and change, and the fact that earlier interventions may lead to greater cumulative impact than those taking part later in life. 
What? There are at least two ways in which evidence from personality psychology can inform decisions about what types of behaviors to try to change. First, the Big Five can organize groups of behaviors, as well as change goals and strategies (Hopwood et al., 2009; Ozer \& Benet-Martinez, 2007; Roberts et al., 2007). For instance, whereas neuroticism tends to be mostly associated with health, happiness, and well-being, conscientiousness is related to work performance and income. The Big Five thus offers a parsimonious framework for organizing outcomes as well as traits, and thereby can provide guidance about how to target specific traits given the outcome of interest. Second, findings related to the course of personality tell us which traits are likely to change, and at which points during the lifespan. As mentioned above, both neuroticism and conscientiousness may represent good intervention targets in young adulthood, particularly for certain young adults who are deviating from the normative trend by becoming more neurotic and/or less conscientious. This is not to say that there are optimal trait levels that should be universally promoted in all people. Indeed, research on person-environment fit indicates that certain environments may call for lower levels in seemingly desirable traits such as agreeableness or conscientiousness. For instance, Denissen et al. (2018) found that highly conscientious individuals had lower earnings in jobs that did not demand high levels in this trait domain. As such, it will be important to target interventions and policy changes towards individual needs and environmental demands.

Who? Perhaps the most intuitive way to use personality trait measures to inform interventions is to select people for interventions based on their personalities. For instance, certain interventions - especially those that require persistence and long-term commitment - may be more effective among conscientious, emotionally stable people. As discussed above, it is also important to consider the role of motivational factors. In particular, success is more likely among 
people who are motivated and believe that change is feasible (Hennecke et al., 2014). Of course, conscientious, emotionally stable, and motivated individuals are also less likely to be the targets of interventions. Cost-benefit analyses that account for both the potential dampening effect of maladaptive personality and the power of the intervention would offer a solution to this specific paradox. At a more general level, this example highlights how a consideration of personality may enhance the efficiency and effectiveness of policy and interventions.

How? Theory and research in personality and clinical science converge on the finding that, as a general rule, any purposeful attempt to change personality should occur frequently and be of sufficient duration to affect changes in habits outside of the intervention period. How long and how frequent interventions must be are empirical questions that can be evaluated in terms of the pace at which self-reinforcing habits develop outside of the treatment and the degree to which changes generalize to multiple psychological domains. Psychotherapy research suggests a mid-level of frequency and time for interventions: more than one session is needed but the most pronounced effects occur relatively soon (Hansen, Lambert, \& Forman, 2002; Roberts et al., 2017). However, the frequency and duration of interventions may differ across individuals and trait domains. A more nuanced understanding of when and how treatments may lead to sustainable change in traits will be essential for developing valid and cost-efficient interventions.

\section{Conclusion}

In conclusion, we hope to have presented a view of personality traits that is not only amenable to purposeful interventions, but also motivates efforts toward that end. For too long, persistent misconceptions of traits have discouraged researchers from viewing traits as viable intervention targets. Countering these claims, the past few decades of research have shown that personality traits are both relatively stable and responsive to interventions. In fact, the potential 
for producing long-term changes that would positively impact individuals across multiple domains suggests that personality traits are ideal targets for interventions designed to improve life success. In some respects, this may seem as an obvious point, as we now know that widely used interventions, such as psychotherapy already can and do change personality traits. It is quite possible that other types of interventions, such as those used in educational and occupational spheres are also changing personality traits and the only reason we lack evidence for this fact is a lack of imagination on the part of the researcher conducting the evaluation of those efforts to include measures of personality traits more than once. And, though the answer to how to change personality may not lead to substantial changes in what we do in interventions, it does invite subtle yet significant shifts in perspectives on how those interventions should be conducted and evaluated. Not only might we focus on personality traits themselves, but we would also suggest that researchers place greater value and emphasis on engendering generalizable and enduring changes that are the hallmark of personality trait development. 


\section{References}

Allemand, M., \& Flückiger, C. (2017). Changing personality traits: Some considerations from psychotherapy process-outcome research for intervention efforts on intentional personality change. Journal of Psychotherapy Integration, 27, 476-494.

Allport, G. W. (1961). Pattern and growth in personality. Oxford, England: Holt, Reinhart \& Winston.

Ashton, M. C., \& Lee, K. (2007). Empirical, theoretical, and practical advantages of the HEXACO model of personality structure. Personality and social psychology review, 11(2), 150-166.

Baumeister, R. F., \& Tice, D. M. (1988). Metatraits. Journal of Personality, 56, 571-598.

Bleidorn, W. (2012). Hitting the road to adulthood: Short-term personality development during a major life transition Personality and Social Psychology Bulletin, 38, 1594-1608.

Bleidorn, W. (2015). What accounts for personality maturation in early adulthood? Current Directions in Psychological Science, 24, 245-252.

Bleidorn, W. \& Hopwood, C. J. Stability and Change in Personality Traits Over the Lifespan (2018), in: D. McAdams, R. Shiner, J. Tackett (eds.), Handbook of Personality Development.

Bleidorn, W., Hopwood, C. J., Lucas, R. E. (2018) Life events and personality trait change. Journal of Personality, 86, 83-96.

Bleidorn, W., Kandler, C., \& Caspi, A. (2014). The behavioral genetics of personality development in adulthood - Classic, contemporary, and future trends. European Journal of Personality, 28, 244-255.

Bleidorn, W., Kandler, C., Riemann, R., Angleitner, A., \& Spinath, F.M. (2009). Patterns and sources of adult personality development: Growth curve analyses of the NEO-PI-R scales in a longitudinal twin study. Journal of Personality and Social Psychology, 97, 142-155. 
Bleidorn, W., Klimstra, T.A., Denissen, J.J.A., Rentfrow, P.J., Potter, J., \& Gosling, S.D. (2013). Personality maturation around the world: A cross-cultural examination of Social Investment Theory. Psychological Science, 24, 2530-2540.

Bleidorn, W., \& Schwaba, T. (2018). Retirement is associated with change in self-esteem. Psychology and Aging, 33, 586-594.

Bogg, T., \& Roberts, B. W. (2004). Conscientiousness and health-related behaviors: a metaanalysis of the leading behavioral contributors to mortality. Psychological bulletin, 130(6), 887.

Borghuis, J., Bleidorn, W. Sijtsma, K., Branje, S. Meus, W. H. J., Denissen, J. J. A. (in press). Longitudinal associations between trait neuroticism and negative daily experiences in adolescence. Journal of Personality and Social Psychology.

Borghuis, J., Denissen, J. J. A., Oberski, D., Sijtsma, K., Meeus, W. H. J., Branje, S., . . . Bleidorn, W. (2017). Big Five personality stability, change, and co-development across adolescence and early adulthood. Journal of Personality and Social Psychology, 113, 641-657.

Briley, D. A., \& Tucker-Drob, E. M. (2014). Genetic and environmental continuity in personality development: A meta-analysis. Psychological Bulletin, 140, 1303.

Caspi, A., \& Moffitt, T. E. (1993). When do individual differences matter? A paradoxical theory of personality coherence. Psychological Inquiry, 4, 247-271.

Costa Jr, P. T., McCrae, R. R., \& Löckenhoff, C. E. (2019). Personality Across the Life Span. Annual Review of Psychology, 70, 423-448.

Damian, R. I., Spengler, M., Sutu, A., \& Roberts, B. W. (in press). Sixteen going on sixty-six: A longitudinal study of personality stability and change across 50 years. Journal of Personality and Social Psychology. 
Damian, R. I., Spengler, M., \& Roberts, B. W. (2017). Whose Job Will Be Taken Over by a Computer? The Role of Personality in Predicting Job Computerizability over the Lifespan. European Journal of Personality, 3, 291-310.

Denissen, J.J.A., Bleidorn, W., Hennecke, M., Luhmann, M., Orth, U., Specht, J., \& Zimmermann, J. (2018). Uncovering the Power of Personality to Shape Income. Psychological Science, 29, 3-13.

Denissen, J.J.A., Luhmann, M. Chung, J.M. Bleidorn, W. Transactions between life events and personality traits across the adult lifespan (2018). Journal of Personality and Social Psychology. Advance online publication. http://dx.doi.org/10.1037/pspp0000196

Fleeson, W. (2001). Toward a structure-and process-integrated view of personality: Traits as density distributions of states. Journal of Personality and Social Psychology, 80, 1011.

Fujita, F., \& Diener, E. (2005). Life satisfaction set point: stability and change. Journal of Personality and Social Psychology, 88, 158.

Funder, D. C. (1991). Global traits: A Neo-Allportian approach to personality. Psychological Science, 2, 31-39.

Geukes, K., van Zalk, M., \& Back, M. D. (2018). Understanding personality development: An integrative state process model. International Journal of Behavioral Development, 42, 43-51.

Hansen, N. B., Lambert, M. J., \& Forman, E. M. (2002). The psychotherapy dose-response effect and its implications for treatment delivery services. Clinical Psychology: science and practice, $9,329-343$

Heckman, J. J., \& Kautz, T. (2012). Hard evidence on soft skills. Labour economics, 19, 451464. 
Hennecke, M., Bleidorn, W., Denissen, J.J.A., \& Wood, D. (2014). A three-part framework for self-regulated personality development across adulthood. European Journal of Personality, 28, 289-299.

Hill, P. L., \& Jackson, J. J. (2016). The invest-and-accrue model of conscientiousness. Review of General Psychology, 20, 141-154.

Hopwood, C. J. (2018). Interpersonal dynamics in personality and personality disorders. European Journal of Personality, 32, 499-524.

Hopwood, C. J., Morey, L. C., Ansell, E. B., Grilo, C. M., Sanislow, C. A., McGlashan, T. H., ... \& Skodol, A. E. (2009). The convergent and discriminant validity of five-factor traits: Current and prospective social, work, and recreational dysfunction. Journal of Personality Disorders, 23(5), 466-476.

Hopwood, C. J., Newman, D. A., Donnellan, M. B., Markowitz, J. C., Grilo, C. M., Sanislow, C. A., ... \& Gunderson, J. G. (2009). The stability of personality traits in individuals with borderline personality disorder. Journal of Abnormal Psychology, 118, 806.

Hopwood, C. J., Thomas, K. M., Markon, K. E., Wright, A. G., \& Krueger, R. F. (2012). DSM-5 personality traits and DSM-IV personality disorders. Journal of abnormal psychology, $121,424$.

Hudson, N. W., \& Fraley, R. C. (2015). Volitional personality trait change: Can people choose to change their personality traits?. Journal of Personality and Social Psychology, 109, 490.

Hudson, N. W., Roberts, B. W., \& Lodi-Smith, J. (2012). Personality trait development and social investment in work. Journal of research in personality, 46, 334-344.

John, O. P., \& Srivastava, S. (1999). The Big Five trait taxonomy: History, measurement, and theoretical perspectives. In L. A. Pervin \& O. P. John (Eds.), Handbook of personality: Theory and research (2nd ed., pp. 102-138). New York: Guilford. 
Jokela, M Kivimäki, M Elovainio, L Keltikangas-Järvinen . Personality and having children: a two-way relationship. Journal of personality and social psychology 96, 218.

Kandler, C., Bleidorn, W., Riemann, R., Spinath, F.M., Thiel, W., \& Angleitner, A. (2010). Sources of cumulative continuity in personality: A longitudinal multiple-rater twin study. Journal of Personality and Social Psychology, 98, 995-1008.

Kandler, C., Kornadt, A. E., Hagemeyer, B., \& Neyer, F. J. (2015). Patterns and sources of personality development in old age. Journal of Personality and Social Psychology, 109, 175.

Kazdin, A. E. (1980). Behavior therapy: Evolution and expansion. In C. E. Thoresen (Ed.), The behavior therapist (pp. 71-78). Monterey, CA: Brooks/Cole.

Kern, M. L., \& Friedman, H. S. (2008). Do conscientious individuals live longer? A quantitative review. Health Psychology, 27, 505.

Kotov, R., Gamez, W., Schmidt, F., \& Watson, D. (2010). Linking “big” personality traits to anxiety, depressive, and substance use disorders: a meta-analysis. Psychological Bulletin, 136,768

Krasner, M.S., Epstein, R.M., Beckman, H., Suchman, A.L., Chapman, B., Mooney, C. J., Quill, T.E. (2009). Association of an educational program in mindful communication with burnout, empathy, and attitudes among primary care physicians. Journal of the American Medical Association, 302, 1284-1293.

Krueger, R. F., Kotov, R., Watson, D., Forbes, M. K., Eaton, N. R., Ruggero, C. J., ... \& Bagby, R. M. (2018). Progress in achieving quantitative classification of psychopathology. World Psychiatry, 17, 282-293.

Leising, D., \& Zimmermann, J. (2011). An integrative conceptual framework for assessing personality and personality pathology. Review of General Psychology, 15, 317. 
Lodi-Smith, J., \& Roberts, B.W. (2012). Concurrent and prospective relationships between social engagement and personality traits in older adulthood. Psychology and Aging, 27, 720727.

Lüdtke, O., Roberts, B.W., Trautwein, U., \& Nagy, G. (2011). A random walk down university avenue: Life paths, life events, and personality trait change at the transition to university life. Journal of Personality and Social Psychology, 101, 620-637.

Markon, K.E., Krueger, R.F., \& Watson, D. (2006). Delineating the structure of normal and abnormal personality: An integrative hierarchical approach. Journal of Personality and Social Psychology, 88, 139-157.

McCrae, R. R., \& Costa Jr, P. T. (2008). A five-factor theory of personality. In O.P. John, R.W. Robins, \& L. A. Pervin (Eds.), Handbook of personality: theory and research (3rd edition). New York, NY: Guilford.

McCrae, R. R., Costa, P. T. J., Ostendorf, F., Angleitner, A., Hrebickova, M., Avia, M. D., .. . Smith, P. B. (2000). Nature over nurture: Temperament, personality, and life span development. Journal of Personality and Social Psychology, 78, 173-186.

Moffitt, T. E., Arseneault, L., Belsky, D., Dickson, N., Hancox, R. J., Harrington, H., ... Caspi, A. (2011). A gradient of childhood self-control predicts health, wealth, and public safety. Proceedings of the National Academy of Sciences, 108, 2693-2698.

Mõttus, R., Kandler, C., Bleidorn, W., Riemann, R., \& McCrae, R. R. (2017). Personality traits below facets: The consensual validity, longitudinal stability, heritability, and utility of personality nuances. Journal of Personality and Social Psychology, 112, 474-490.

Morey, L. C., \& Hopwood, C. J. (2013). Stability and change in personality disorders. Annual Review of Clinical Psychology, 9, 499-528.

Mroczek, D. K. (2014). Personality plasticity, healthy aging, and interventions. Developmental Psychology, 50, 1470-1474. 
Mroczek, D. K., \& Spiro III, A. (2003). Modeling intraindividual change in personality traits: Findings from the Normative Aging Study. The Journals of Gerontology Series B: Psychological Sciences and Social Sciences, 58, 153-165.

Noftle, E. E., \& Robins, R. W. (2007). Personality predictors of academic outcomes: big five correlates of GPA and SAT scores. Journal of personality and social psychology, 93(1), 116.

Oei, T.P., \& Jackson P. (1980). Long-term effects of group and individual social skills training with alcoholics. Addictive Behaviors, 5, 129-36.

Ormel, J., Jeronimus, B. F., Kotov, R., Riese, H., Bos, E. H., Hankin, B., ... \& Oldehinkel, A. J. (2013). Neuroticism and common mental disorders: meaning and utility of a complex relationship. Clinical Psychology Review, 33, 686-697.

Orth, U., \& Robins, R. W. (2014). The development of self-esteem. Current Directions in Psychological Science, 23, 381-387.

Ozer, D. J., \& Benet-Martinez, V. (2006). Personality and the prediction of consequential outcomes. Ann. Rev. Psychol., 57, 401-421.

Piedmont, R. L. (2001). Cracking the plaster cast: Big Five personality change during intensive outpatient counseling. Journal of Research in Personality, 35, 500-520.

Reise, S. P., \& Waller, N. G. (1993). Traitedness and the assessment of response pattern scalability. Journal of Personality and Social Psychology, 65, 143-151.

Roberts, B. W. (2018). A revised sociogenomic model of personality traits. Journal of Personality, 86, 23-35.

Roberts, B. W., \& Bogg, T. (2004). A longitudinal study of the relationships between conscientiousness and the social-environmental factors and substance-use behaviors that influence health. Journal of Personality, 72, 325-354. 
Roberts, B. W., Hill, P. L., \& Davis, J. P. (2017). How to change conscientiousness: The sociogenomic trait intervention model. Personality Disorders: Theory, Research, and Treatment, 8, 199.

Roberts, B. W., \& Jackson, J. J. (2008). Sociogenomic personality psychology. Journal of Personality, 76, 1523-1544.

Roberts, B. W., Kuncel, N. R., Shiner, R., Caspi, A., \& Goldberg, L. R. (2007). The power of personality: The comparative validity of personality traits, socioeconomic status, and cognitive ability for predicting important life outcomes. Perspectives on Psychological Science, 2, 313-345.

Roberts, B. W., Luo, J., Briley, D. A., Chow, P. I., Su, R., \& Hill, P. L. (2017). A systematic review of personality trait change through intervention. Psychological Bulletin, 143, 117.

Roberts, B. W., Walton, K. \& Viechtbauer, W. (2006). Patterns of mean-level change in personality traits across the life course: A meta-analysis of longitudinal studies. Psychological Bulletin, 132, 1-25.

Roberts, B.W., \& Wood, D. (2006). Personality development in the context of the neosocioanalytic model of personality. In D. Mroczek \& T. Little (Eds.), Handbook of personality development (pp. 11-39). Mahwah, NJ: Erlbaum.

Rosenström, T., Gjerde, L. C., Krueger, R. F., Aggen, S. H., Czajkowski, N. O., Gillespie, N. A., ... \& Ystrom, E. (in press). Joint factorial structure of psychopathology and personality. Psychological Medicine.

Schwaba, T. \& Bleidorn, W. (2018). Individual differences in personality change across the adult lifespan. Journal of Personality, 86, 450-464.

Schwaba, T. \& Bleidorn, W. (in press). Personality development across the transition to retirement. Journal of Personality and Social Psychology. 
Schwaba, T., Luhmann, M., Denissen, J.J.A., \& Bleidorn, W. (2018). Openness to experience and culture-openness transactions across the lifespan. Journal of Personality and Social Psychology. 15, 118-136.

Schwaba, T., Robins, R. W., Grijalva, E., \& Bleidorn, W. Does openness to experience matter in love and work? Evidence from a 24-year longitudinal study (in press). Journal of Personality.

Shanahan, M. J., Hill, P. L., Roberts, B. W., Eccles, J., \& Friedman, H. S. (2014). Conscientiousness, health, and aging: the life course of personality model. Developmental Psychology, 50, 1407.

Shapiro, D. A., \& Shapiro, D. (1982). Meta-analysis of comparative therapy outcome studies: a replication and refinement. Psychology Bulletin, 92, 581-604.

Small, B. J., Hertzog, C., Hultsch, D. F., \& Dixon, R. A. (2003). Stability and change in adult personality over 6 years: Findings from the Victoria Longitudinal Study. The Journals of Gerontology Series B: Psychological Sciences and Social Sciences, 58, 166-176.

Smith, M. L., Glass, G. V, \& Miller, T. I. (1980). The benefits of psychotherapy. Baltimore: Johns Hopkins University Press.

Specht, J., Bleidorn, W., Denissen, J.J.A., Hennecke, M., Hutteman, R., Kandler, C., ...Zimmermann, J. (2014). What drives adult personality development? A comparison of theories and empirical evidence. European Journal of Personality, 28, 216-230.

Soto, C. J. (in press). How replicable are links between personality traits and consequential life outcomes? The Life Outcomes of Personality Replication Project. Psychological Science.

Srivastava, S., John, O. P., Gosling, S. D., \& Potter, J. (2003). Development of personality in early and middle adulthood: Set like plaster or persistent change?. Journal of Personality and Social Psychology, 84, 1041. 
Takahashi, Y., Edmonds, G. W., Jackson, J. J., \& Roberts, B. W. (2013). Longitudinal correlated changes in conscientiousness, preventative health-related behaviors, and self-perceived physical health. Journal of Personality, 81, 417-427.

Turkheimer, E. (2000). Three laws of behavior genetics and what they mean. Current Directions in Psychological Science, 9, 160-164.

van Scheppingen, M. A., Denissen, J. J. A., \& Bleidorn, W. (in press) Stability and change in self-control during the transition to parenthood. European Journal of Personality. van Scheppingen, M. A., Jackson, J. J., Specht, J., Hutteman, R., Denissen, J. J. A., \& Bleidorn, W. (2016). Personality development during the transition to parenthood: A test of social investment theory. Social Psychological and Personality Science, 7, 452-462

Vittengl, J. R., Clark, L. A., \& Jarrett, R. B. (2003). Interpersonal problems, personality pathology, and social adjustment after cognitive therapy for depression. Psychological Assessment, 15, 29.

Wagner, J., Becker, M., Lüdtke, O., \& Trautwein, U. (2015). The first partnership experience and personality development: A propensity score matching study in young adulthood. Social Psychological and Personality Science, 6, 455-463.

Wagner, J., Ram, N., Smith, J., \& Gerstorf, D. (2016). Personality trait development at the end of life: Antecedents and correlates of mean-level trajectories. Journal of Personality and Social Psychology, 111, 411.

Wortman, J., Lucas, R. E., \& Donnellan, M. B. (2012). Stability and change in the Big Five personality domains: Evidence from a longitudinal study of Australians. Psychology and Aging, 27, 867.

Wright, A. G., \& Simms, L. J. (2015). A metastructural model of mental disorders and pathological personality traits. Psychological Medicine, 45, 2309-2319. 
Wrzus, C., \& Roberts, B. W. (2017). Processes of personality development in adulthood: The TESSERA framework. Personality and Social Psychology Review, 21, 253-277. 
Table 1. Questions and Answers about Personality Trait Change.

\begin{tabular}{|c|c|}
\hline Question & Answer \\
\hline What are personality traits? & $\begin{array}{l}\text { Relatively enduring patterns of thoughts, feelings, and } \\
\text { behaviors that distinguish individuals from each other }\end{array}$ \\
\hline What is personality trait change? & $\begin{array}{l}\text { Rank-order: how people change relative to one another on a } \\
\text { trait over a certain period of time } \\
\text { Mean-level: how groups change on average on a trait over a } \\
\text { certain period of time } \\
\text { Individual-level: how individuals change differently than the } \\
\text { group average over a certain period of time }\end{array}$ \\
\hline $\begin{array}{l}\text { How stable and changeable are } \\
\text { personality traits? }\end{array}$ & $\begin{array}{l}\text { Rank-order: quite stable but not completely } \\
\text { Mean-level: traits change characteristically over the lifespan, } \\
\text { generally towards greater psychological maturity in young and } \\
\text { middle adulthood } \\
\text { Individual-level: not everyone follows mean-level trends, } \\
\text { people differ relative to one another in their individual } \\
\text { trajectories }\end{array}$ \\
\hline What drives personality change? & $\begin{array}{l}\text { There is evidence for the influence of both genes and } \\
\text { experiences in shaping personality stability and change }\end{array}$ \\
\hline $\begin{array}{l}\text { Can personality be changed through } \\
\text { intervention? }\end{array}$ & $\begin{array}{l}\text { Psychotherapy findings and emerging intervention research } \\
\text { suggest that traits can be changed on purpose. }\end{array}$ \\
\hline How can traits be changed? & $\begin{array}{l}\text { Trait change should be desirable and feasible, desired changes } \\
\text { should be practiced often, ideally parallel to changes in self- } \\
\text { concept }\end{array}$ \\
\hline $\begin{array}{l}\text { Why not focus on something that is } \\
\text { easier to change? }\end{array}$ & The impacts of personality are enduring and broad \\
\hline
\end{tabular}


Figure 1. Rank-order, mean-level, and individual differences in change (adapted from Morey \& Hopwood, 2013). Panels show hypothetical longitudinal data of four individuals. Panel A shows rank-order change and individual differences in change in the absence of mean-level change. Panel B shows mean-level change in the absence of rank-order change or individual differences in change. Panel $C$ shows individual differences in change in the absence of mean-level change or rank-order change. See text for further explanation.

A

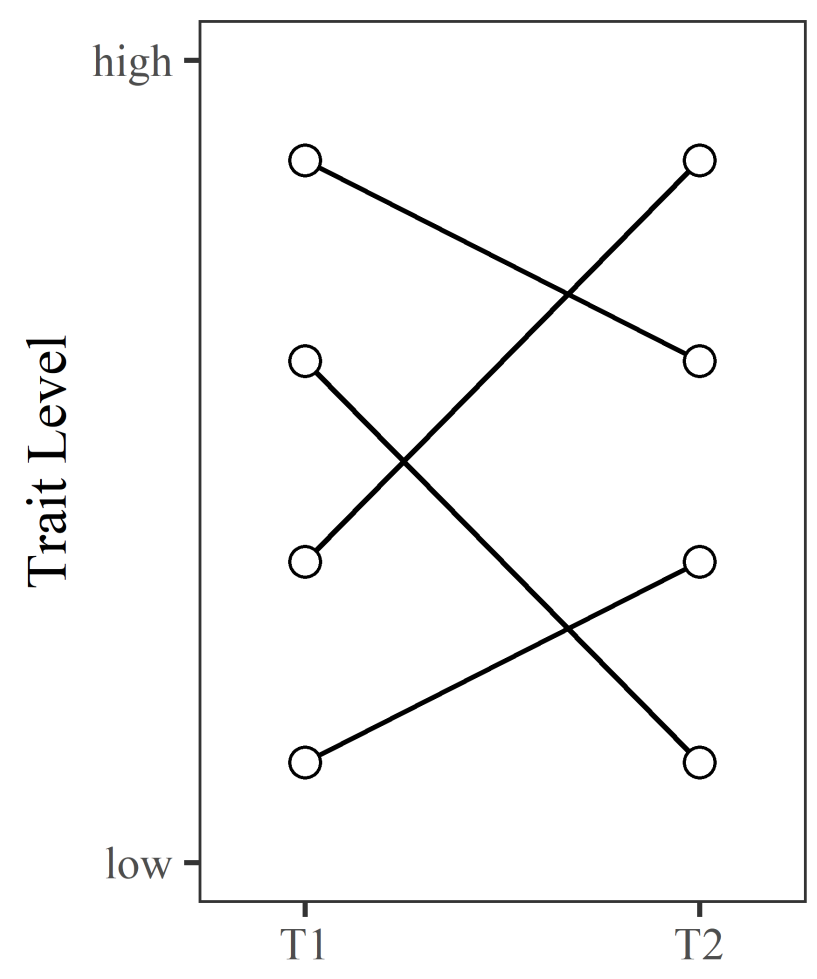

B

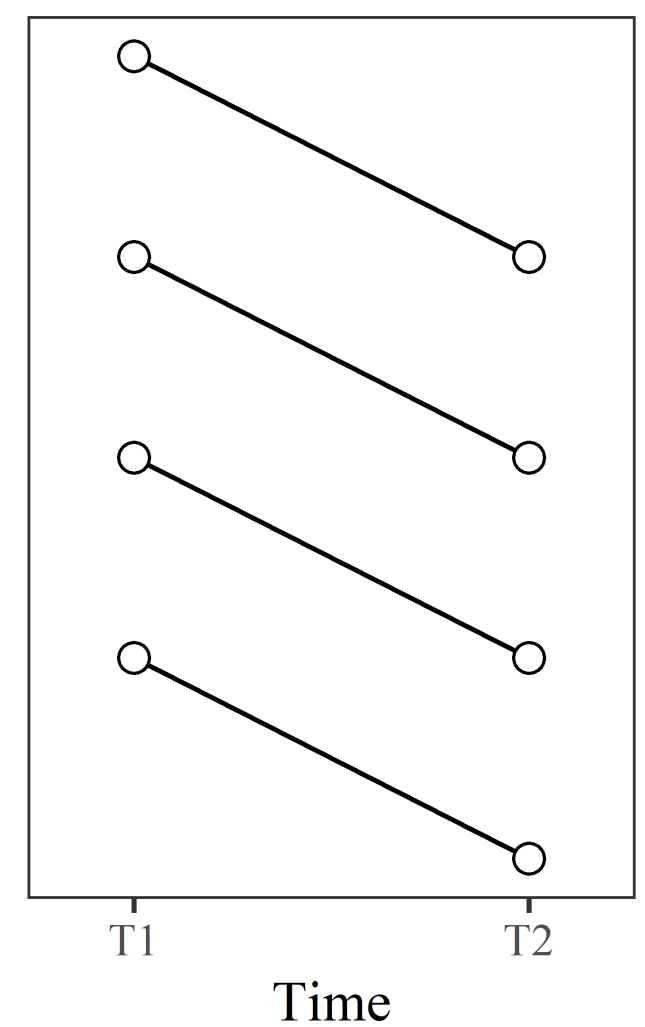

C

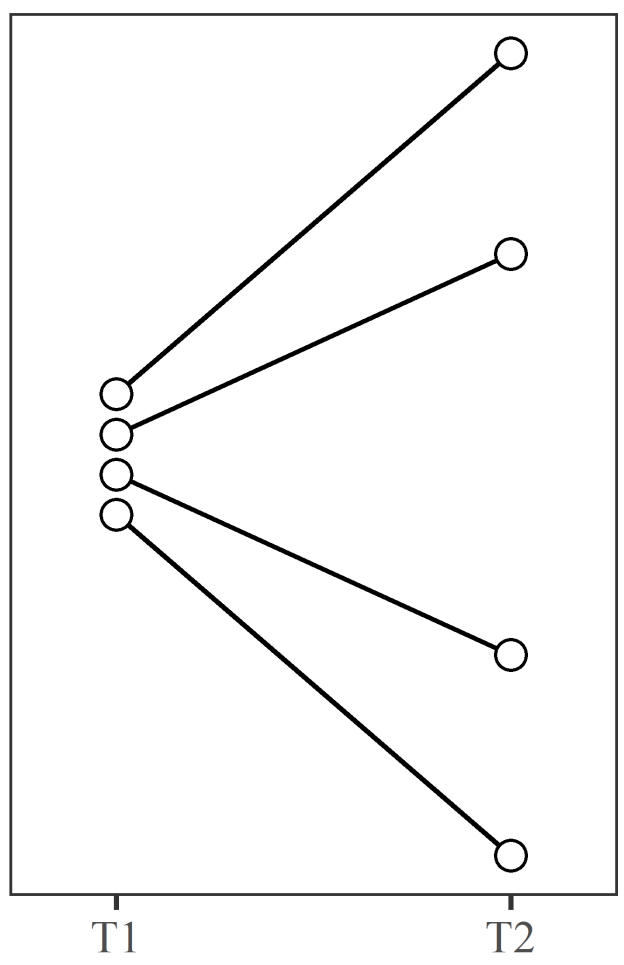

